\title{
Polymorphonuclear Pancreatic Elastase Measurement
}

National Cancer Institute

\section{Source}

National Cancer Institute. Polymorphonuclear Pancreatic Elastase Measurement. NCI

Thesaurus. Code C82029.

The determination of the amount of polymorphonuclear pancreatic elastase present in a sample. 